J-SANAK: Jurnal Kajian Anak

(p-ISSN: 2686-5343 |e-ISSN: 2715-7989)

Vol. (3)(01), (Juli-Desember)(2021), (Halaman)(27-37)

DOI: https://doi.org/10.24127/j-sanak.v3i01.597

\title{
MODEL PEMBELAJARAN ANAK USIA DINI BERBASIS EDUTAINMENT: STUDI PUSTAKA
}

\author{
Hijriati $^{1}$ \\ UIN Ar-Raniry Banda Aceh \\ hijriati@ar-raniry.ac.id \\ Mohammad Irsyad ${ }^{2}$ \\ IAIN Pekalongan \\ mohammad.irsyad@iainpekalongan.ac.id
}

\begin{abstract}
ABSTRAK
Penelitian ini bertujuan untuk membahas dengan konsep edutainment merupakan suatu kegiatan pembelajaran dimana pelaksanaannya lebih mengedepankan kesenangan dan kebahagiaan dalam rangka mencapai tujuan pembelajaran. Tujuannya adalah agar pembelajar bisa mengikuti dan mengalami proses pembelajaran dalam suasana yang gembira, menyenangkan, menghibur, dan mencerdaskan. Metode penelitian studi Pustaka dengan Menyusun landasan teori dalam pembelajaran yang menyenangkan. Hasil penelitian ini adalah Apabila dikontekskan dengan Pendidikan Anak Usia Dini, maka dunia anak adalah dunia bermain. Bermain adalah metode belajar yang paling efektif. Anak-anak belajar dari segala kegiatan yang mereka lakukan. Kuncinya adalah bagaimana mengubah kegiatan bermain menjadi pengalaman belajar. Belajar berbasis edutainment adalah salah satu kunci untuk meraih keberhasilan dalam kegiatan pembelajaran.
\end{abstract}

Kata Kunci: Model, Pembelajaran, Edutainment, Anak

Received 10-02-2021; Received in revised form 17-11-2021 ; Accepted 31-12-2021

\begin{abstract}
This study aims to discuss the concept of edutainment which is a learning activity where the implementation prioritizes fun and happiness in order to achieve learning objectives. The goal is that students can follow and experience the learning process in a happy, fun, entertaining, and educational atmosphere. Literature study research method by developing a theoretical foundation in fun learning. The results of this study are when contextualized with Early Childhood Education, then the world of children is the world of play. Play is the most effective learning method. Children learn from all the activities they do. The key is how to turn play activities into learning experiences. Edutainment-based learning is one of the keys to success in learning activities.
\end{abstract}

Keywords :Model, Learning, Edutainment, Child. 
J-SANAK: Jurnal Kajian Anak

(p-ISSN: 2686-5343 |e-ISSN: 2715-7989)

Vol. (3)(01), (Juli-Desember)(2021), (Halaman)(27-37)

DOI: https://doi.org/10.24127/j-sanak.v3i01.597

\section{A. PENDAHULUAN}

Kehadiran seorang guru dan sejumlah pembelajar di dalam kelas, tidak berarti proses pendidikan berlangsung secara otomatis. Bila ada proses pengajaran, tidak berarti pasti diikuti dengan proses pembelajaran. Paradigma positivistik yang telah merasuki dunia pendidikan ini, seringkali membuat suasana pembelajaran menjadi kaku dan menegangkan.

Berangkat dari kondisi tersebut, dirasa perlu adanya suatu konsep pembelajaran yang kiranya bisa menjadi solusi. Sebuah konsep pembelajaran yang mampu menjembatani dan menghadirkan terciptanya suasana pembelajaran yang asyik dan menyenangkan, penuh kehangatan dan cinta kasih sehingga kecerdasan anak akan dapat tumbuh dan berkembang secara optimal.

Apabila dikontekskan dengan Pendidikan Anak Usia Dini, maka dunia anak adalah dunia bermain. Bermain adalah metode belajar yang paling efektif. Anakanak belajar dari segala kegiatan yang mereka lakukan. Kuncinya adalah bagaimana mengubah kegiatan bermain menjadi pengalaman belajar. Ketika anak merasa aman dan nyaman, ia akan mampu belajar dengan baik. Bagi anak kecil yang sedang belajar menghafal kata-kata yang berlawanan, seperti kata atas dan bawah, bisa sambil bermain.

\section{B. PEMBAHASAN}

\section{Pengertian Edutainment}

Kata edutainment terdiri atas dua kata, yakni education dan entertainment. Education artinya pendidikan, dan entertainment artinya hiburan. Edutainment dari segi bahasa memiliki arti pendidikan yang menyenagkan. Sementara dari segi terminologi, edutainment as a form of entertainment that is designed to be educational. Jadi, edutainment bisa didefinisikan sebagai proses pembelajaran yang didesain dengan memadukan antara muatan pendidikan dan hiburan secara harmonis sehingga aktivitas pembelajaran berlangsung menyenangkan (Hamruni, 2008).

Konsep belajar berwawasan edutainment mulai diperkenalkan secara formal sejak tahun 1980-an dan telah menjadi satu metode pembelajaran yang sukses dan membawa pengaruh yang luar biasa pada bidang pendidikan dan pelatihan di era milenium ini.

Konsep sendiri secara bahasa bisa diartikan sebagai pendapat, rancangan, gagasan, pandangan, cita-cita yang telah ada dalam pikiran. Berdasarkan pengertian konsep tersebut, maka konsep edutainment bisa diartikan sebagai sejumlah gagasan, pandangan, ide-ide, pemikiran tentang edutainment yang terdapat dalam teori-teori pembelajaran quantum. 
J-SANAK: Jurnal Kajian Anak

(p-ISSN: 2686-5343 |e-ISSN: 2715-7989)

Vol. (3)(01), (Juli-Desember)(2021), (Halaman)(27-37)

DOI: https://doi.org/10.24127/j-sanak.v3i01.597

Belajar yang menyenangkan, menurut konsep edutainment bisa dilakukan dengan menyelipkan humor dan permainan (games) ke dalam proses pembelajaran, atau bisa juga dengan cara lain, misalnya dengan menggunakan metode bermain peran (roleplay), demonstrasi, dan multimedia. Tujuannya adalah agar pembelajar bisa mengikuti dan mengalami proses pembelajaran dalam suasana yang gembira, menyenangkan, menghibur, dan mencerdaskan.

Ada dua kualitas belajar yang harus dikembangkan dalam diri murid guna mewujudkan pembelajaran yang menyenangkan, yakni:

a. Belajar dengan menjadi (learning to be) akan menghasilkan pribadi yang mandiri.

b. Belajar untuk belajar (learning to learn) dengan terus-menerus secara aktif.

Banyak istilah yang digunakan sejalan dengan konsep tersebut, antara lain "PAKEM" atau "Pembelajaran Aktif, Kreatif, Efektif dan Menyenangkan." Disamping itu, muncul juga istilah yang muncul di Jawa Tengah dengan sebutan "PAIKEM Gembrot" atau "Pembelajaran aktif, Inovatif, Kreatif, Efektif, Menyenangkan, Gembira dan Berbobot." Dan di Jayapura muncul pula sebutan "Pembelajaran MATOA (Menyenangkan Atraktif Terukur Orang Aktif)" yang mempunyai arti Pembelajaran yang menyenangkan, guru dapat menyajikan dengan atraktif/ menarik dengan hasil yang terukur sesuai yang diharapkan peserta didik (orang) belajar secara aktif. (Pangastuti, 2014)

1. Perubahan Paradigma

Dalam dunia pendidikan, paradigma lama tentang proses belajar mengajar bersumber pada teori tabula rasa dari John Locke. John Locke berpendapat bahwa pikiran seorang anak seperti kertas putih bersih dan siap menunggu coretan-coretan gurunya. Otak seorang anak ibarat sebuah botol kosong yang siap diisi dengan segala ilmu pengetahuan dan kebijaksanaan dari gurunya. Dalam pola ini, tugas seorang guru adalah member dan tugas murid adalah menerima. Guru memberikan informasi dan mengharapkan murid untuk menghafal dan mengingatnya. Pola lain adalah mengisi botol kosong dengan air pengetahuan. Pada pola ini, murid adalah penerima pengetahuan yang pasif dan guru adalah pemilik pengetahuan yang nantinya akan dihafal oleh murid (suyadi, 2010)

Sebenarnya, tuntutan dalam dunia pendidikan sudah banyak berubah. Paradigma di atas sudah tidak bisa dipertahankan. Teori, penelitian, dan pelaksanaan belajar mengajar membuktikan bahwa para guru sudah harus mengubah paradigma pengajaran. Mel Silberman, salah satu tokoh pembelajaran quantum, mencoba mengubah paradigma pembelajaran yang ada dengan mencermati pernyataan Confucius, yang kemudian dimodifikasi. Confucius menyatakan:

What I hear, I forget (apa yang saya dengar, saya lupa) 
J-SANAK: Jurnal Kajian Anak

(p-ISSN: 2686-5343 |e-ISSN: 2715-7989)

Vol. (3)(01), (Juli-Desember)(2021), (Halaman)(27-37)

DOI: https://doi.org/10.24127/j-sanak.v3i01.597

What I see, I remember (apa yang saya lihat, saya ingat)

What I do, I understand (apa yang saya lakukan, saya paham)

Tiga pernyataan sederhana ini memberikan bobot yang penting bagi pembelajaran aktif. Lalu, Mel Silberman memodifikasi dan memperluas tiga pernyataan tersebut menjadi apa yang ia sebut dengan paham Belajar Aktif.

What I hear, I forget (apa yang saya dengar, saya lupa)

What I hear and see, I remember a little (apa yang saya dengar dan lihat, saya ingat sedikit)

What I hear, see and ask questions about or discuss with someone else, I begin to understand (apa yang saya dengar, lihat, dan tanyakan atau diskusikan dengan beberapa teman, saya mulai paham)

What I hear, see, discuss, and do, I acquire knowledge and skill (apa yang saya dengar, lihat, diskusikan, dan lakukan, saya memperoleh pengetahuan dan ketrampilan)

What I teach to another, I master (apa yang saya ajarkan pada orang lain, saya menguasainya) (Silberman, 2005)

Konsep edutainment berusaha membalik paradigma belajar pasif di atas. Di dalam konsep ini, muridlah yang lebih banyak aktif, sehingga konsekuensi belajar lebih besar. Konsep ini juga akan membantu murid untuk belajar tidak hanya mendengar, tetapi juga melihat, mempertanyakan, dan mendiskusikan. Dengan demikian, guru lebih menekankan pada penciptaan suasana kelas yang aktif dan menggairahkan melalui berbagai strategi belajar daripada subyek yang atoritatif.

2. Karakteristik Edutainment Dalam Pembelajaran PAUD

Beberapa prinsip yang menjadi karakteristik dari konsep edutainment, yakni:

a. Konsep edutainment adalah suatu rangkaian pendekatan dalam pembelajaran untuk menjembatani jurang yang memisahkan antara proses mengajar dan proses belajar, sehingga diharapkan bisa meningkatkan hasil belajar.

b. Konsep dasar edutainment berupaya agar pembelajaran yang terjadi berlangsung dalam suasana yang kondusif dan menyenangkan. Ada tiga asumsi yang menjadi landasannya, yakni:

1) Perasaan gembira. Suasana gembira akan memengaruhi cara otak dalam memproses, menyimpan, dan mengambil informasi dengan mudah. Dalam upaya menciptakan kondisi ini, maka konsep edutainment mencoba memadukan pendidikan dan hiburan.

2) Mengembangkan emosi positif anak. Ketika suatu pelajaran melibatkan emosi positif yang kuat, umumnya pelajaran tersebut akan terekam dengan kuat pula dalam ingatan. Oleh karena itu, dibutuhkan kreativitas guru dan orang tua untuk menciptakan permainanpermainan yang dapat menjadi wadah dan sarana anak untuk belajar, misalnya melalui drama, warna, humor, dan lain-lain. 
J-SANAK: Jurnal Kajian Anak

(p-ISSN: 2686-5343 |e-ISSN: 2715-7989)

Vol. (3)(01), (Juli-Desember)(2021), (Halaman)(27-37)

DOI: https://doi.org/10.24127/j-sanak.v3i01.597

Emosi positif dapat meningkatkan kekuatan otak, keberhasilan, dan kekuatan diri.

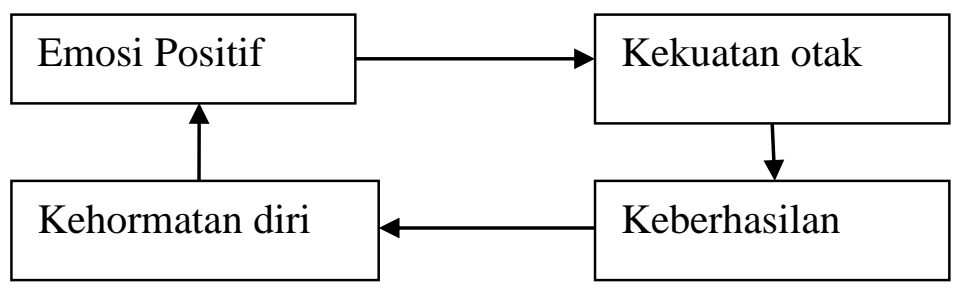

Skema peran emosi positif

Kegembiraan merupakan ekspresi emosi yang riang, bahagia, dan menyenangkan. Anak yang mengalami kegembiraan diwujudkan dengan ekspresi senyum dan tidak menangis.

3) Optimalisasi potensi nalar anak secara jitu mampu membuat loncatan prestasi belajar secara berlipat ganda.

c. Anak didik yang dimotivasi dengan tepat dan diajar dengan cara yang benar (cara yang menghargai gaya atau style dan keinginan mereka), maka mereka dapat mencapai hasil belajar yang optimal. Pendekatan yang digunakan dalam konsep ini adalah anak didik akan diperkenalkan dengan cara dan proses belajar yang benar sesuai dengan kepribadian dan keunikan mereka masing-masing.

Apabila dikontekskan dengan Pendidikan Anak Usia Dini, maka seorang pendidik harus dapat merangsang dan membangun munculnya seluruh potensi kecerdasan anak, bukan malah mematikan potensi tersebut. Oleh karena itu, pendidik anak usia dini perlu memahami karakteristik anak usia dini, yaitu: 1) Anak bukanlah miniatur orang dewasa. 2) Anak masih dalam tahap berkembang. 3) Setiap anak itu unik. 4) Dunia anak adalah dunia bermain. 5) Anak belum tahu salah benar. 6) Setiap karya anak berharga. 7) Setiap anak butuh rasa aman. 8) Setiap anak peneliti dan penemu.

\section{Nuansa dan Implementasi Edutainment PAUD}

Ada beberapa model pembelajaran yang mempunyai keterkaitan dengan edutainment, diantaranya adalah: Setidaknya ada beberapa cakupan edutainment dalam model pembelajaran Active Learning, yakni:

a. Mengatur Tata Ruang Kelas.

Pengaturan kelas yang baik dan dengan pola yang berbeda-beda akan mampu menjadikan anak lebih semangat, memperhatikan tata ruang akan menghadirkan suasana yang baru dan nantinya akan membuat peserta didik senang. 
J-SANAK: Jurnal Kajian Anak

(p-ISSN: 2686-5343 |e-ISSN: 2715-7989)

Vol. (3)(01), (Juli-Desember)(2021), (Halaman)(27-37)

DOI: https://doi.org/10.24127/j-sanak.v3i01.597

b. Keterampilan Mengelola Kelas.

Pengelolaan kelas adalah keterampilan guru untuk menciptakan dan memelihara kondisi belajar yang optimal dan mengembalikannya apabila terjadi gangguan proses belajar mengajar. Beberapa prinsip penggunaan keterampilan pengelolaan kelas adalah:

1) Kehangatan dan keantusiasan guru akan menciptakan iklim kelas yang menyenangkan.

2) Tantangan, nuansa baru dengan ide-ide yang menantang akan menjadikan fokus peserta didik lebih stabil.

3) Bervariasi dalam penggunaan media, gaya dan interaksi belajar mengajar.

c. Strategi Pembelajaran.

Perbedaan model belajar peserta didik menuntut pendidik untuk mampu melakukan reformulasi terhadap strategi pembelajaran yang digunakan. Kemampuan melakukan improvisasi pada strategi pembelajaran akan membantu menjadi penyemangat dengan memberikan nuansa baru dalam proses pembelajaran (Ratna, 2014)

2. Accelerated Learning (beda AL \& Active Learning)

Accelerated Learning atau disingkat AL adalah sebuah pendekatan komperehensif dalam pembelajaran yang mengintegrasikan seluruh komponen dalam pembelajaran, seperti nuansa sekolah, keunikan peserta didik dan proses pembelajarannya. Oleh Bobby DePorter istilah AL didefinisikan sebagai model pembelajaran yang memungkinkan peserta didik untuk belajar dengan kecepatan yang mengesankan dengan upaya yang normal, dan dibarengi kegembiraan.

Metode belajar alami yang melibatkan seluruh indra dan emosi. Konsep belajar ini juga disebut dengan pendekatan S-A-V-I (Somatis-AuditoriVisual-Intelektual). Dengan pendekatan ini, diharapkan akan terjadi percepatan dan peningkatan dalam kemampuan dan hasil belajar (Suyadi, 2010)

Berikut ini akan dikemukakan secara singkat mengenai konsep dasar nuansa edutainment dalam Accelerated Learning:

a. Prinsip-prinsip Accelerated Learning

Berhasil atau tidaknya penggunaan Accelerated Learning sangat ditentukan oleh konsistensi berpegang teguh pada prinsip-prinsip Accelerated Learning:

1) Belajar melibatkan seluruh pikiran dan tubuh.

2) Belajar adalah berkreasi, bukan mengonsumsi.

3) Kerja sama.

4) Pembelajaran berlangsung pada banyak tingkat secara stimulant. 
J-SANAK: Jurnal Kajian Anak

(p-ISSN: 2686-5343 |e-ISSN: 2715-7989)

Vol. (3)(01), (Juli-Desember)(2021), (Halaman)(27-37)

DOI: https://doi.org/10.24127/j-sanak.v3i01.597

5) Belajar berasal dari mengajarkan pekerjaan itu sendiri melalui umpan balik.

6) Melibatkan emosi positif.

b. Peran emosi dalam belajar.

Untuk melibatkan emosi dalam pembelajaran, guru harus dapat menciptakan kesenangan dalam belajar dengan cara menjalin hubungan dan menyingkirkan segala ancaman dari suasana belajar. Ada tiga langkah untuk dapat menciptakan suasana belajar yang menyenangkan. Pertama, afirmasi (sugesti). Kedua, mengakui. Dan ketiga, merayakan kerja keras. (Suyadi, 2010)

c. Teori otak

Salah satu tujuan dari tahap persiapan siklus Accelerated Learning adalah menciptakan perasaan (emosi) positif dalam diri pembelajar. Hal ini dapat dilakukan dengan mengoptimalkan kinerja sistem limbik dalam otak. Fungsi otak bagian ini akan mendorong yang bersangkutan untuk bekerja sama, bukan bersaing. Di samping itu, setiap pembelajaran harus melibatkan fungsi neokorteks otak. Sebab, optimalisasi bagian otakini dapat membantu cara berpikir, mengolah informasi, berimajinasi, dan menciptakan makna serta nilai bagi dirinya sendiri.

Neurosains modern telah menemukan bahwa otak terbagi menjadi dua bagian, kiri dan kanan. Kedua belahan otak ini oleh sebagian ilmuwan neurosains disebut sebagai otak rasional dan otak intuitif. Belahan otak kiri bekerja secara linier, rasional, kritis, analitis, dan abstrak. Sementara belahan otak kanan bekerja secara subjektif, rasional, holistik, sintetik, dan konkret. (Suyadi, 2010)

3. Quantum Learning

Quantum Learning bisa jadi merupakan teori pembelajaran yang handal pada saat ini. Penggabungan dari beberapa model pembelajaran seperti, accelerated learning, multiple intelligences, brain research, neuro linguistic programming, learning modalities, experiental learning, dan cooperative learning terpadu dalam pengetahuan tunggal yang menghasilkan suatu pembelajaran yang sangat berenergi.

Teori belajar quantum membekali para siswa dengan pengetahuan tentang berbagai gaya belajar sesuai dengan modalitas masing-masing siswa. Pengetahuan dalam bidang inilah yang dikenal dengan istilah "belajar cara belajar". Cara belajar yang tepat akan sangat bermanfaat, terutama dalam membentuk keterampilan bersikap positif, motivasi, dan kreativitas. Cara belajar yang dipelajari dalam teori ini adalah teknik membaca cepat, membuat catatan efektif, menulis canggih, dan menghafal secara menakjubkan. (Suyadi, 2010) 
J-SANAK: Jurnal Kajian Anak

(p-ISSN: 2686-5343 |e-ISSN: 2715-7989)

Vol. (3)(01), (Juli-Desember)(2021), (Halaman)(27-37)

DOI: https://doi.org/10.24127/j-sanak.v3i01.597

Ada beberapa komunikasi negatif yang harus guru atau pun orang tua hindari agar tidak timbul keyakinan negative dalam diri seorang anak, diantaranya: 1) Kalimat yang berkonotasi memerintah. "Cepat mandi, keburu sore!". 2) Kalimat yang berkonotasi menyalahkan."Bu guru bilang juga apa, main tidak usah sambil lari-lari. Akibatnya, jatuh kan kamu”. 3) Kalimat yang berkonotasi meremehkan. "Sudah umur lima tahun, masih saja pipis di celana". 4) Kalimat yang berkonotasi melabeli. "Dasar anak nakal, sukanya keluyuran dan nggak bisa diam". 5) Kalimat yang berkonotasi membandingkan. "Sewaktu usiamu, kakakmu sudah bisa membaca dan menghitung dengan baik. Kok kamu susah sekali sich?" 6) Kalimat yang berkonotasi mengancam. "Awas kalau tidak mau makan, besok nggak akan ibu ajak pergi ke pasar!" 7) Kalimat yang berkonotasi menasehati. "Siapa suruh tidak tidur siang dan main terus, lihat sekarang kamu jadi rewel toh?" 8) Kalimat yang berkonotasi membohongi. "Mainan itu dikembalikan kepada yang punya ya, besok bu guru belikan kamu di pasar". (tanpa berdosa, sang ibu tidak menepati janji keesokan harinya) 9) Kalimat yang berkonotasi menghibur. "Nich, dah ibu belikan mainan yang kamu minta. Sudah jangan nangis, ya!” 10) Kalimat yang berkonotasi mengkritik. "Adik sudah bagus mau tampil di pentas sekolah, tapi sayangnya suaranya masih kurang keras tadi". 11) Kalimat yang berkonotasi menyindir. "Ke sekolah telat lagi kan, bangunnya kepagian sich". 12) Kalimat yang berkonotasi ?. "Gara-gara kamu suka rame di kelas, makanya bu guru ngasih nilai jelek”. (Handayani, 2011)

b. Belajar secara menyeluruh.

Global Learning adalah cara efektif dan alamiah bagi seseorang untuk mempelajari segala sesuatu. Cara belajar ini mengambil contoh bagaimana cara anak mempelajari sesuatu. Sekadar contoh, ketika anak disodori mainan tertentu, maka ia akan mengamati, kemudian menggenggam, meremas, mengangkat, menggoyang, memutar dan membantingnya. Setelah itu, ia akan memasukkan mainan tersebut ke dalam mulutnya, untuk kemudian dimainkan sesuai dengan perkembangan kognitifnya. Nah, kegiatan seperti ini mirip dengan kegiatan ilmuwan ketika melakukan penelitian. Ia menggunakan seluruh indranya untuk menyelidiki obyek. Inilah yang disebut dengan Global Learning. (Suyadi, 2010)

c. AMBAK

AMBAK adalah singkatan dari Apa Manfaat Bagiku. Teori Quantum Learning menyarankan setiap siswa atau pelajar untuk mempertanyakan, "Apa manfaat bagiku?" terlebih dahulu sebelum memperlajari segala hal. Hal ini diperlukan untuk membangkitkan motivasi atas hal yang dipelajari tersebut. 
J-SANAK: Jurnal Kajian Anak

(p-ISSN: 2686-5343 |e-ISSN: 2715-7989)

Vol. (3)(01), (Juli-Desember)(2021), (Halaman)(27-37)

DOI: https://doi.org/10.24127/j-sanak.v3i01.597

d. Menata lingkungan belajar

Penataan lingkungan ini juga dapat diwujudkan dengan pemberian iringan musik dan pemberian jeda saat belajar. Pemberian iringan musik menjadi penting dalam quantum learning karena musik sesungguhnya berhubungan dan mempengaruhi kondisi fisiologis seseorang.

Dalam pembelajaran, pemberian jeda yang berulang-ulang dianjurkan untuk setiap jenis sesi belajar. Ada dua alasan untuk ini. Pertama, dalam setiap masa belajar, yang paling diingat dengan baik adalah informasi yang dipelajari pada saat pertama dan terakhir. Maka dari itu, jika seorang siswa sering mendapat jeda, dia akan mengingat lebih banyak dari seluruh informasi. Kedua, ketika pikiran siswa menjadi letih, perubahan keadaan mental yang terjadi selama jeda akan menyegarkan kembali sel-sel otaknya untuk langkah berikutnya. (Hamruni, 2008)

e. Memahami gaya belajar

Gaya belajar adalah kunci untuk mengembangkan kemampuan belajar di sekolah. Menyadari bagaimana cara menyerap dan mengolah informasi dapat menjadikan belajar dan berkomunikasi lebih mudah.

4. Macam-macam Edutainment dalam Pembelajaran Anak Usia Dini.

Ada berbagai macam bentuk strategi edutainment dalam pendidikan anak usia dini, adapun bentuk-bentuk ragam edutainment di antaranya:

a. Bermain

Para pakar mengatakan bahwa dunia anak adalah dunia bermain, bermain memiliki peran penting dalam mengembangkan segala aspek perkembangan anak, menurut Gordon \& Browne dalam Moeslichatoen, bermain merupakan kagiatan yang memberikan kepuasan bagi diri sendiri.

b. Karya Wisata

Karya wisata merupakan salah satu metode melaksanakan kegiatan pengajaran dengan cara mengamati dunia sesuai dengan kenyataan yang ada dengan secara langsung yang meliputi manusia hewan, tumbuh-tumbuhan dan benda-benda lainnya, dengan mengamati secara langsung anak memperoleh kesan yang sesuai dengan pengamatannya.

c. Bercakap-cakap

Dalam kegiatan bercakap-cakap tiap anak yang terlibat dalam kegiatan itu ingin membicarakan segala sesuatu yang diketahui, dimiliki dan dialami kepada anak lain atau gurunya. Bercakap-cakap mengandung arti belajar mewujudkan kemampuan berbahasa reseptif dan ekspresif, anak akan mengembangkan bermacam kosa kata dalam berbagai tema yang akan mengacu pengembangan berbagai aspek perkembangan anak.

d. Demonstrasi

Yang dimaksud dengan Metode Demonstrasi Eksperimen ialah suatu upaya atau praktik dengan menggunakan peragaan yang ditujukan 
J-SANAK: Jurnal Kajian Anak

(p-ISSN: 2686-5343 |e-ISSN: 2715-7989)

Vol. (3)(01), (Juli-Desember)(2021), (Halaman)(27-37)

DOI: https://doi.org/10.24127/j-sanak.v3i01.597

pada peserta didik yang tujuannya ialah agar semua siswa lebih mudah dalam memahami dan mempraktikkan dari apa yang telah diperolehnya dan dapat mengatasi suatu permasalahan apabila terdapat perbedaan.

e. Bercerita

Metode bercerita merupakan pemberian pengalaman belajar bagi anak usia dini dengan membawakan cerita kepada anak secara lisan, cerita yang dibawakan guru harus menarik, mengundang perhatian anak dan tidak lepas dari tujuan pendidikan anak usia dini.

f. Proyek

Metode proyek merupakan salah satu cara pemberian pengalaman belajar dengan menghadapkan anak dengan persoalan-persoalan sehari-hari yang harus dipecahkan secara berkelompok, metode proyek berasal dari gagasan John Dewey tentang konsep learning by doing yakni proses perolehan hasil belajar dengan mengerjakan tindakan-tindakan tertentu sesuai dengan tujuannnya, terutama proses penugasan anak tentang bagaimana melakukan pekerjaan yang terdiri atas serangkaian tingkah laku untuk mencapai tujuan misalnya melipat kertas, memasang tali sepatu, menganyam, membentuk model binatang atau bangunan dan sebagainya.

g. Pemanfaatan Komputer

Komputer kini tengah menjadi salah satu tren media pembelajaran alternatif untuk anak usia dini. Saat ini kian berkembangnya softwaresoftware dengan program tertentu dalam bentuk CD interaktif untuk membantu pembelajaran anak usia dini (Pangastuti, 2014).

\section{KESIMPULAN}

Konsep pembelajaran berbasis edutainment yaitu pembelajaran yang berisi tentang gagasan atau ide-ide untuk melakukan kegiatan belajar yang asyik dan menyenangkan. Belajar berbasis edutainment adalah salah satu kunci untuk meraih keberhasilan dalam kegiatan pembelajaran. Ada beberapa model pembelajaran yang bernuansa edutainment, diantaranya adalah Active Learning, Accelerated Learning, dan Quantum Learning. Dimana semua model pembelajaran ini apabila diterapkan dalam pembelajaran akan berlangsung dengan menyenangkan, sehingga akan memudahkan anak dalam memahami materi pembelajaran.

\section{DAFTAR PUSTAKA}

Asmawati, Luluk. 2014. Perencanaan Pembelajaran PAUD. Bandung: PT. Remaja Rosdakarya

Fadlilah, M., dkk. 2014. Edutainment Pendidikan Anak Usia Dini, Jakarta: Kencana.

Copyright (C) 2020, Universitas Muhammadiyah Metro| 36 
J-SANAK: Jurnal Kajian Anak

(p-ISSN: 2686-5343 |e-ISSN: 2715-7989)

Vol. (3)(01), (Juli-Desember)(2021), (Halaman)(27-37)

DOI: https://doi.org/10.24127/j-sanak.v3i01.597

Hamruni. 2008. Konsep Edutainment dalam Pendidikan Islam, Yogyakarta: UIN Sunan Kalijaga.

Handayani. 2011. Arifah, Smart Parenting with Love, Cet. Ke-2, Jakarta: Progressio.

Hasan, Maimunah. 2013. Pendidikan Anak Usia Dini,Jogjakarta: DIVA Press.

IYaumi, Muhammad dan Ibrahim, Nurdin. 2013. Pembelajaran Berbasis Kecerdasan Jamak, Jakarta: Kencana.

Murtiningsih, Siti, 2004. Pendidikan Alat Perlawanan; Teori Pendidikan Radikal Paulo Freire, Yogyakarta: Resist Book.

Ngalimun, 2014. Strategi dan Model Pembelajaran, Cet. Ke-3, Yogyakarta: Aswaja Pressindo.

Pangastuti, Ratna, 2014. Edutainment PAUD, Yogyakarta: Pustaka Pelajar. Suyadi, 2010. Psikologi Belajar PAUD, Yogyakarta: Pedagogia. 